STI prevention, screening and management, using clinical screening algorithms. 28868 clients requesting HIV counselling and testing were registered from 2007 to 2009 trough a database.

Objectives To assess rate and risks factors of STI among vulnerable youth attending counselling and testing facilities, including STI management.

Methods Descriptive analysis and logistic regression was performed on the database with SPSS 17. The dependent variable is "having had an STI the last 3 months". The independents variables are- "having multiple partners in the three past months", "consistent use of condom" and socio-demographic characteristics.

Results In all 5.1\% of HIV counselled and tested clients approached for STI on-site screening had STI the last 3 month, while STI prevalence among this population is $1.9 \%$. Multiple partners $(\mathrm{OR}=4.5 ; \quad \mathrm{p}=0.000)$, no consistent use of condom $(0 \mathrm{R}=1.3$; $\mathrm{p}=0.002)$ were significantly associate to IST infection. The level of instruction $(\mathrm{OR}=1.3 ; \mathrm{p}=0.000)$ and $\operatorname{sex}(\mathrm{OR}=0.6 ; \mathrm{p}=0.000)$ were the significant socio-demographic characteristic associated with STI. Conclusions Data findings indicate that having had STI in the last 3 month may be a motivation for youth which are attending HIV counselling and testing facilities in Atacora/Donga in Benin, and "high numbers of partners" is the main risk factor for STI among them. Then, scaling up HIV counselling and testing services may be a right way for STI prevention, screening and management. Finding suggests that such intervention (counselling) focused on reducing number of partner, improved to promotion of condom use, may reduce STI incidence among vulnerable youth that need further investigation.

\section{P1-S2.31 MEAN STREETS VS MAIN STREET - MORE STREET YOUTH REPORT STIS, MULTIPLE SEXUAL PARTNERS AND LOWER CONDOM USE COMPARED TO THEIR PEERS IN THE GENERAL POPULATION}

doi:10.1136/sextrans-2011-050108.88

\begin{abstract}
${ }^{1} \mathrm{~L}$ Fang, ${ }^{1} \mathrm{~S}$ A Klar, ${ }^{2} \mathrm{C}$ Tawse, ${ }^{3} \mathrm{D}$ Friedman, ${ }^{4} \mathrm{D}$ Taylor, ${ }^{5} \mathrm{~J}$ Gratrix, ${ }^{6} \mathrm{~J}$ Wiley, ${ }^{7} \mathrm{~J}$ Wright, ${ }^{8} \mathrm{M}$ Rossi, ${ }^{1} \mathrm{~T}$ Wong, ${ }^{1} \mathrm{G}$ C Gayaraman, ${ }^{1} T$ Team Enhanced Street Youth Surveillance. ${ }^{1}$ Public Health Agency of Canada, Ottawa, Canada; ${ }^{2}$ Capital District Health Authority, Canada; ${ }^{3}$ Ottawa Public Health, Canada; ${ }^{4} B C$ Centre for Disease Control, Canada; ${ }^{5}$ Alberta Health Services, Canada; ${ }^{6}$ Cadham Provincial Laboratory, Canada; ${ }^{7}$ Public Health Services, Saskatoon Health Region, Canada; ${ }^{8}$ Sick Kids Hospital and University of Toronto, Canada
\end{abstract}

Background The burden of sexually transmitted infections (STIs) and engagement in high risk behaviours is assumed to be greater in street-involved youth (SIY) than the general population, but the magnitude of this difference has rarely been described.

Methods Preliminary data from four sites $(n=734)$ of E-SYS cycle 6 (Enhanced Surveillance of Street Youth, 2009-present) and the corresponding metropolitan centres of CCHS 2009 (Canadian Community Health Survey) were analysed. E-SYS is a repeated cross-sectional study of SIY (15-24 years), who completed an interviewer-administered questionnaire and provided blood and urine samples for STI, HIV and HCV testing. CCHS is a representative cross-sectional over the phone survey of Canadians, which collects data on health determinants and status. The CCHS sample was restricted to youth aged $15-24$ years (weighted $n=708589$, unweighted $n=780$ ). Estimates of self-reported STIs, sexual behaviours, substance use and demographics are reported with 95\% CIs and IORs.

Results Compared to their peers in the general population, a greater proportion of SIY were male, between 15 and 19 years old, Aboriginal, Canadian-born, without a high school diploma and have higher rates of regular binge drinking, smoking and illicit drug use (Abstract P1-S2.31 table 1). A greater proportion of SIY (23.8\% vs
$3.5 \%)$ reported sexualities other than straight/heterosexual. A higher proportion of SIY had had sexual intercourse (95.5\% vs $67.4 \%$ ) and had been diagnosed with an STI (18.7\% vs 3.8\%). Sexually active SIY reported a lower proportion of condom use at last intercourse (35.4\% vs $52.3 \%$ ). The median age at first intercourse was 14 years among SIY and 17 years among youth in the general population. The median number of sexual partners for youth in the general population was one (last 12 months) compared to two partners for SIY (last 3 months).

Abstract P1-S2.31 Table 1 Demographics, use of illicit drugs and alcohol, and sexual behaviours among youth aged 15-24 years who took part in Canadian Community Health Survey 2009 (CCHS) and Enhanced Surveillance of Street Youth (E-SYS) cycle 6.

\begin{tabular}{|c|c|c|}
\hline & $\begin{array}{l}\text { CCHS } 2009 \\
\text { (Percentage, 95\% Cl }\end{array}$ & $\begin{array}{l}\text { E-SYS Cycle } 6 \\
\text { (Percentage, 95\% CI) }\end{array}$ \\
\hline \multicolumn{3}{|l|}{ Demographics } \\
\hline Males & 52.81 (52.69 to 52.93 ) & 63.39 (59.78 to 66.88 ) \\
\hline Age $15-19$ years & 38.67 (38.26 to 38.49$)$ & 56.87 (53.27 to 60.47$)$ \\
\hline Aboriginal & 6.22 (6.16 to6.28) & 41.55 (37.99 to 45.12 ) \\
\hline Born in Canada & 75.47 (75.37 to 75.57$)$ & 93.44 (91.65 to 95.24$)$ \\
\hline High School Completion* & 93.87 (93.82 to 93.92$)$ & 25.81 (21.69 to 29.92 ) \\
\hline \multicolumn{3}{|l|}{ Drugs and Alcohol } \\
\hline Binge Drink Regularly† & $10.57(10.50$ to 10.65$)$ & 34.65 (31.15 to 38.15$)$ \\
\hline Smoke Daily & 11.86 (11.65 to 11.80$)$ & 76.13 (73.23 to 79.18$)$ \\
\hline $\begin{array}{l}\text { Illicit Drug use Last } \\
\text { 12P1-S2.07 months } \ddagger\end{array}$ & 24.86 (24.77 to 24.95$)$ & 94.28 (92.34 to 95.85$)$ \\
\hline \multicolumn{3}{|l|}{ Sexual Behaviours } \\
\hline $\begin{array}{l}\text { Sexuality - "Straight" or } \\
\text { "Heterosexual" }\end{array}$ & 96.57 (96.54 to 96.60$)$ & 76.16 (73.08 to 79.24$)$ \\
\hline Ever Had Intercourse & 60.84 (60.72 to 60.95 & 95.5 (94.01 to 97.00$)$ \\
\hline $\begin{array}{l}\text { Age First Intercourse (Median, } \\
\text { IQR in Years) } \S\end{array}$ & 17 (16 to 18$)$ & 14 (13 to 16$)$ \\
\hline Condom Use Last Intercourse§ & 52.34 (52.24 to 52.45$)$ & 35.42 (40.14 to 47.32 ) \\
\hline $\begin{array}{l}\text { Number of partners } \\
\text { (Median, IQR)§, }\end{array}$ & 1 (1 to 2$)$ & $2(1$ to 3$)$ \\
\hline Ever had an STI§ & $3.83(3.79$ to 3.87$)$ & 18.74 (15.91 to 21.57$)$ \\
\hline
\end{tabular}

Note - Preliminary data analysis only comes four E-SYS sites and corresponding census metropolitan areas from CCHS.

${ }^{*}$ Among those aged 19 and over.

†Binge drinking more than once a week.

$\ddagger$ Excludes using cannabis once.

$\S$ Asked from only those who indicated having had sexual intercourse.

qLast 3 months for ESYS, Last 12 months for CCHS.

Conclusions Street-involved youth are more vulnerable to the social determinants of health, which partly explains the marked differences between them and their peers in the general Canadian population. Lower levels of education and other structural factors, combined with higher levels of substance use and riskier sexual practices may contribute to the higher burden of STIs among SIY. The magnitude of differences between the two groups highlights the need for continued efforts using a multi-sectoral approach to address the needs of this population though targeted interventions and programs.

\section{P1-S2.32 DO AS I THINK, NOT AS I DO: THE DISCORDANCE BETWEEN PERCEPTION OF RISK FOR STBBIS AND SEXUAL RISK BEHAVIOURS AMONG CANADIAN STREET- INVOLVED YOUTH}

doi:10.1136/sextrans-2011-050108.89

${ }^{1} \mathrm{~L}$ Fang, ${ }^{1} \mathrm{~S}$ A Klar, ${ }^{2} \mathrm{D}$ Friedman, ${ }^{3} \mathrm{~J}$ Gratrix, ${ }^{4} \mathrm{M}$ Rossi, ${ }^{5} \mathrm{C}$ Tawse, ${ }^{6} \mathrm{D}$ Taylor, ${ }^{7} \mathrm{~J}$ Wright, ${ }^{8} \mathrm{~J}$ Wylie, ${ }^{1} \mathrm{~T}$ Wong, ${ }^{1} \mathrm{G} \mathrm{C}$ Jayaraman, ${ }^{9} \mathrm{~T}$ Team for the Enhanced Street Youth Surveillance. ${ }^{1}$ Public Health Agency of Canada, Ottawa, Canada; ${ }^{2}$ Ottawa Public Health, Ottawa, Canada; ${ }^{3}$ Alberta Health Services, Edmonton, Canada; ${ }^{4}$ Hospital for Sick 